\title{
Working posture analysis of sweet whey powder handling at CV Cita Nasional warehouse using OVAKO Working Posture Analysis (OWAS)
}

\author{
Manik Mahachandra ${ }^{1,}$, Heru Prastawa ${ }^{1}$, and Dhialma Yonathan Susilo ${ }^{1}$ \\ ${ }^{1}$ Industrial Engineering Department, Faculty of Technology, Universitas Diponegoro, Semarang, \\ Central Java, Indonesia 50275
}

\begin{abstract}
In this 4.0 industrial era, some material handlings are still conducted manually by human. One example is in the warehouse area of CV Cita Nasional, a milk processing factory in Kopeng, Central Java. Workers are repetitively unloading a $25 \mathrm{~kg}$ sack of sweet whey powder from truck to warehouse area. Therefore, this study was carried out to investigate the musculoskeletal disorders risks on that workers manual handling activity. The OVAKO Working Posture Analysis System (OWAS) was chosen to be applied in the evaluation steps. For each activity in the unloading process, OWAS score category of 3 (improvements are necessary as soon as possible) were resulted on lifting, 2 (improvements are necessary in the long-term future) on carrying, and 3 on lowering the load. Consequently, a trolley was then designed to minimize the risks. The trolley was designed based on Indonesian anthropometry dimensions. Applying this proposed tool, lifting and lowering activities were then categorized in OWAS score of 2 , whilst carrying was resulted in OWAS score of 1 (improvements are not necessary). This applied study was valuable in order to minimize the musculoskeletal disorders risks on such manual material handling activity, not only in the current workplace, but also in similar situation of industries. Keywords: anthropometry, manual material handling, musculoskeletal risks, OVAKO Working Posture Analysis System (OWAS), tool design
\end{abstract}

\section{Introduction}

CV Cita Nasional is one of the milk processing factory, located in Kopeng, Salatiga, West Java, Indonesia. The milk products, branded "Susu Segar Nasional", are very famous in the community. One of the main ingredients in the milk processing is the sweet whey powder. This ingredient made of secondary product of processed cheese, which involved enzyme as the coagulation method to absorb water, generate emulsification, and result foams. Whey protein is also commonly added in the processed food to increase the nutrition. The sweet whey powder used in this factory is produced by Poland company, ordered regularly every

\footnotetext{
*Corresponding author: manik.mahachandra@gmail.com
} 
six months, and stored in specific warehouse in this factory. At the warehouse, the company hired six workers to handle all the storages. From a preliminary study, we configured that the workers' activity in storage handling were mostly conducted manually, which theoretically will develop high risks of musculoskeletal disorders (MSDs). Such prolonged situation, if not well controlled, will lead into injury and accident at work.

A manual material handling of sweet whey powder starts at lifting a $25 \mathrm{~kg}$ sack from truck to warehouse area. The load is usually carried on the top of worker's head, while his hands maintain the load along the process. As stated in [1], a lifting products task is more ergonomically hazardous for MSDs than the pulling task. Musculoskeletal disorder is a pathology condition that affect the normal function of musculoskeletal system of human body, including nervous, tendon, muscle, and supporting structure like discus intervertebral [2]. The disorder occurs as a result of repetitive activity and/or awkward working posture. The symptoms are including pain, sore, or cramps while working, or after work hours. As [3] reported in their research, $47 \%$ warehouse operators were involved in lower back injury, while $31 \%$ had knee problem and $21 \%$ of them experienced neck injury. Moreover, these numbers were related to 200 days of absenteeism. However, musculoskeletal disorders not only affected the workers' physical condition, but also the company. High number of absenteeism, high turnover, low motivation, and high stress level has been reported along with workers' injuries occurrences [4][5].

To prevent further problems of CV Cita Nasional warehouse workers, this study aimed to minimize the musculoskeletal risk of injury. Body postures and movements while working were captured and analyzed. A working tool was then designed to minimize the injury risk.

\section{Method}

\subsection{Participants}

Six male workers were contributed in the study as participants. All of them performed at least one activity in lifting, carrying, and lowering the sack of powder. They were all familiar with the layout and handling procedure, so that no particular preparation was needed before the data collection.

\subsection{OVAKO Working Posture Analysis}

The main data in this study were the working postures while moving the sweet whey powder from trucks to warehouse area. These postures were analyzed using the OVAKO Working Posture Analysis System (OWAS). OWAS was developed in a steel industry company, Ovako Oy, in Finland in 1973 to define the workload in the overhauling of iron smelting ovens [6]. OWAS is a suitable tool for analyzing the musculoskeletal risk when the whole body parts are working simultaneously, just like moving the load in this current study.

OWAS verifies the safety level of the most common work postures for the back (four postures), arms (three postures), and legs (seven postures), as well as the weight of the load handled (three categories). The quantification of each body parts is shown in Table 1, so that the whole body posture is described by those four body parts using a four digit code. It was then classified into four action categories indicating the needs for ergonomic changes, as presented by Fig. 1 . 
Table 1. OWAS action level.

\begin{tabular}{llc}
\hline \multicolumn{1}{c}{ Action } & Digit \\
\hline \multirow{3}{*}{ Back } & Straight & 1 \\
& Bent & 2 \\
& Twisted & 3 \\
& Bent and twisted & 4 \\
\hline \multirow{4}{*}{ Arms } & Both arms below shoulder level & 1 \\
& One arm at or above shoulder level & 2 \\
& Both arms at or above shoulder level & 3 \\
\hline \multirow{4}{*}{ Legs } & Sitting & 1 \\
& Standing on two straight legs & 2 \\
& Standing on one straight leg & 3 \\
& Standing or squatting on two bent legs & 4 \\
& Standing or squatting on one bent leg & 5 \\
& Kneeling & 6 \\
& Walking & 7 \\
\hline \multirow{3}{*}{ Load } & Less or equal to $10 \mathrm{Kg}$ & 1 \\
& Greater than $10 \mathrm{Kg}$ and less or equal to $20 \mathrm{Kg}$ & 2 \\
& Greater than $20 \mathrm{Kg}$ & 3 \\
\hline
\end{tabular}

\begin{tabular}{|c|c|c|c|c|c|c|c|c|c|c|c|c|c|c|c|c|c|c|c|c|c|c|}
\hline \multirow{4}{*}{ Back } & \multirow{4}{*}{ Arms } & \multicolumn{21}{|c|}{ Legs } \\
\hline & & \multirow{2}{*}{\multicolumn{3}{|c|}{$\frac{1}{\text { Load }}$}} & \multirow{2}{*}{\multicolumn{3}{|c|}{$\frac{2}{\text { Load }}$}} & \multicolumn{3}{|c|}{3} & \multicolumn{3}{|c|}{4} & \multicolumn{3}{|c|}{5} & \multicolumn{3}{|c|}{6} & \multicolumn{3}{|c|}{7} \\
\hline & & & & & & & & & Load & & & Lod & & & $.0 \mathrm{ac}$ & & & Load & & & oad & \\
\hline & & 1 & 2 & 3 & 1 & \begin{tabular}{|l|}
2 \\
\end{tabular} & 3 & 1 & \begin{tabular}{|l|}
2 \\
\end{tabular} & 3 & 1 & 2 & 3 & \begin{tabular}{l|l}
1 \\
\end{tabular} & 2 & 3 & 1 & \begin{tabular}{|l|}
2 \\
\end{tabular} & 3 & 1 & 2 & 3 \\
\hline \multirow{3}{*}{1} & 1 & 1 & 1 & 1 & 1 & 1 & 1 & 1 & 1 & 1 & 2 & 2 & 2 & 2 & 2 & 2 & 1 & 1 & 1 & 1 & 1 & 1 \\
\hline & 2 & 1 & 1 & 1 & 1 & 1 & 1 & 1 & 1 & 1 & 2 & 2 & 2 & 2 & 2 & 2 & 1 & 1 & 1 & 1 & 1 & 1 \\
\hline & 3 & 1 & 1 & 1 & 1 & 1 & 1 & 1 & 1 & 1 & 2 & 2 & 3 & 2 & 2 & 3 & 1 & 1 & 1 & 1 & 1 & 2 \\
\hline \multirow{3}{*}{2} & 1 & 2 & 2 & 3 & 2 & 2 & 3 & 2 & 2 & 3 & 3 & 3 & 3 & 3 & 3 & 3 & 2 & 2 & 2 & 2 & 3 & 3 \\
\hline & 2 & 2 & 2 & 3 & 2 & 2 & 3 & 2 & 3 & 3 & 3 & 4 & 4 & 3 & 4 & 4 & 3 & 3 & 4 & 2 & 3 & 4 \\
\hline & 3 & 3 & 3 & 4 & 2 & 2 & 3 & 3 & 3 & 3 & 3 & 4 & 4 & 4 & 4 & 4 & 4 & 4 & 4 & 2 & 3 & 4 \\
\hline \multirow{3}{*}{3} & 1 & 1 & 1 & 1 & 1 & 1 & 1 & 1 & 1 & 2 & 3 & 3 & 3 & 4 & 4 & 4 & 1 & 1 & 1 & 1 & 1 & 1 \\
\hline & 2 & 2 & 2 & 3 & 1 & 1 & 1 & 1 & 1 & 2 & \begin{tabular}{|l|}
4 \\
\end{tabular} & 4 & 4 & 4 & 4 & 4 & 3 & 3 & 3 & 1 & 1 & 1 \\
\hline & 3 & 2 & 2 & 3 & 1 & 1 & 1 & 2 & 3 & 3 & 4 & 4 & 4 & 4 & 4 & 4 & 4 & 4 & 4 & 1 & 1 & 1 \\
\hline \multirow{3}{*}{4} & 1 & 2 & 3 & 3 & 2 & 2 & 3 & 2 & 2 & 3 & 4 & 4 & 4 & 4 & 4 & 4 & 4 & 4 & 4 & 2 & 3 & 4 \\
\hline & 2 & 3 & 3 & 4 & 2 & 3 & 4 & 3 & 3 & 4 & 4 & 4 & 4 & 4 & 4 & 4 & 4 & 4 & 4 & 2 & 3 & 4 \\
\hline & 3 & 4 & 4 & 4 & 2 & \begin{tabular}{l|}
3 \\
\end{tabular} & 4 & 3 & 3 & 4 & 4 & 4 & 4 & 4 & 4 & 4 & 4 & 4 & 4 & 2 & 3 & 4 \\
\hline \multicolumn{23}{|c|}{ INTERPRETATION OF THE RESULT } \\
\hline \multicolumn{23}{|c|}{1 -No actions required } \\
\hline \multicolumn{23}{|c|}{2 - Corrective actions required in the near future } \\
\hline \multicolumn{23}{|c|}{$\begin{array}{l}3 \text { - Corrective actions should be done as soon as possible } \\
4-\text { Corrective }\end{array}$} \\
\hline \multicolumn{23}{|c|}{4 - Corrective actions for improvement required immediately } \\
\hline
\end{tabular}

Fig. 1. OWAS evaluation and result interpretation. 


\subsection{Additional Data}

Besides the captures of posture while working, some other primary data were also collected in the analysis, such as quantity of sweet whey powder, sack dimensions, and warehouse dimensions. Deep interview with the workers were also conducted to gather their complaints about the manual material handling process in existing condition, as well as ideas in minimizing the complaints in order to improve the quality of working.

\subsection{OWAS Data Compilation}

Posture data of each working movements while moving the sweet whey powder were collected as picture (.jpg) and video (.mov) using camera. There were 16 piles of powder sack in the warehouse. However, three heights of sack pile were chosen to represent the variety of activities, i.e. low, medium, and high. Each capture of body parts was then graded using the OWAS action, as listed in Table 1. Video data were used for helping the grading process. If there were more than one position of body part, the higher number of action level was chosen. OWAS scores were calculated and categorized using ErgoFellow 3.0 software, which was developed by FBF Sistemas Brazil.

\subsection{Tool Design Apparatus}

After examining the OWAS scores of existing conditions, a working tool was then designed for helping the handling process, in order to minimize the OWAS scores. Design process of the working tool was carried out using CATIA V5, a computer-aided design software by Dassault Systèmes French.

\section{Results and Discussion}

\subsection{Existing Condition}

Some pictures of the handling process were shown in Fig. 2. As stated before, the activities captured are for stacking the low pile, medium pile, and high pile of powder sack.
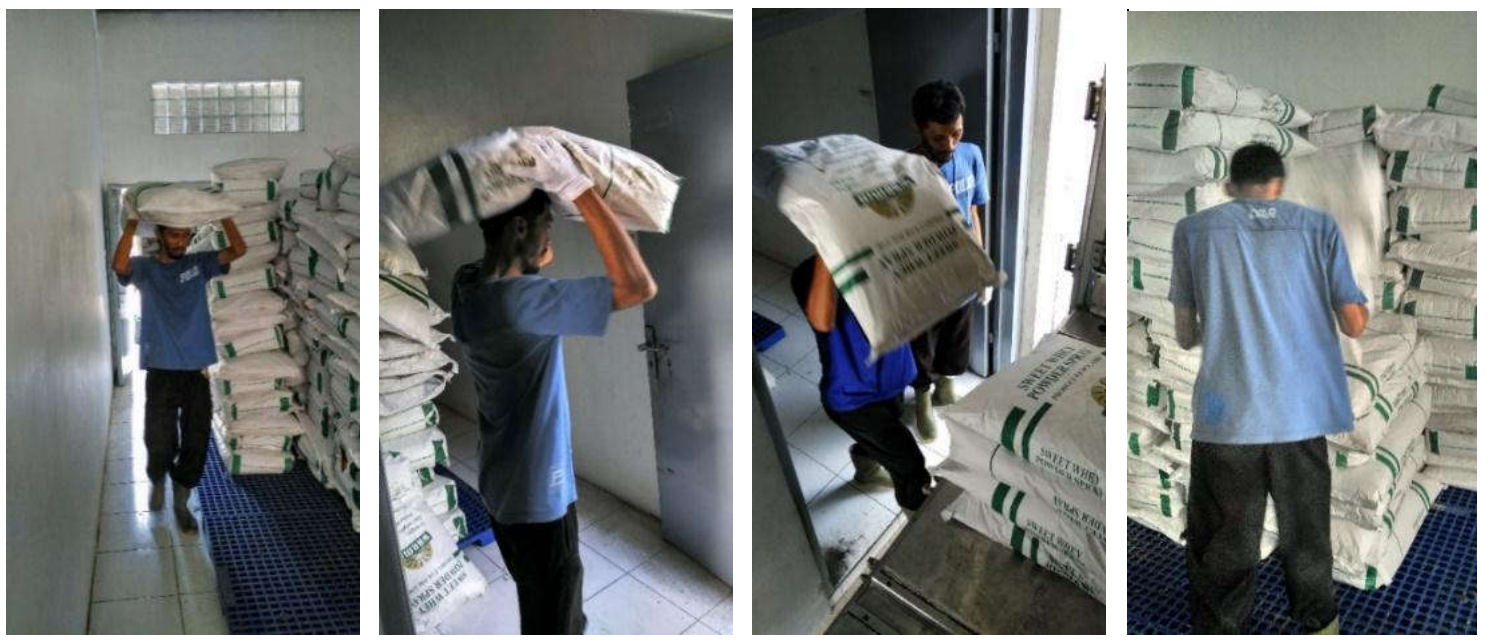

Fig. 2. Postures of handling process.

The OWAS scores for each pictures were then identified. When more than one positions were captured, the highest score was selected. The results are summarized in Table 2. 
Table 2. OWAS scores of handling process.

\begin{tabular}{clll}
\hline \multicolumn{1}{c}{ Pile } & Activity & Digit & \multicolumn{1}{c}{ Interpretation } \\
\hline \multirow{4}{*}{ Low } & Lifting & 3 & Corrective actions should be done as soon as possible \\
& Carrying & 2 & Corrective actions required in the near future \\
& Lowering & 3 & Corrective actions should be done as soon as possible \\
\hline \multirow{4}{*}{ Medium } & Lifting & 3 & Corrective actions should be done as soon as possible \\
& Carrying & 2 & Corrective actions required in the near future \\
& Lowering & 3 & Corrective actions should be done as soon as possible \\
\hline \multirow{4}{*}{ High } & Lifting & 3 & Corrective actions should be done as soon as possible \\
& Carrying & 2 & Corrective actions required in the near future \\
& Lowering & 3 & Corrective actions should be done as soon as possible \\
\hline
\end{tabular}

As displayed above, all activities of moving the sweet whey powder shown high risks of musculoskeletal disorders. As a summarize, the handling process needs corrective actions as soon as possible. The results were based on the poor condition of lifting, carrying, and lowering the load, whether in low pile, medium pile, or high pile of powder.

In the lifting process, the workers bent their back while reaching the load. Both of their arms were in the lower position than the shoulders. They were also standing on bended knees. Additionally, the load they lifted was more than 20 kilograms.

In the carrying process, the workers back were straight, while both arms were higher than the shoulders position. Workers were walking through the process, and carrying more than 20 kilograms of load.

In the lowering process, the workers bent their back when lowering load in the low and medium height of sack pile, while in the high pile they can kept the back straight. On the low and medium height of pile, both arms were lower than the shoulders. Both arms were higher than the shoulders when they stacked in high pile. On all height of pile, they were standing on one bent leg, with a more than 20 kilograms of load.

As known widely, bending posture was highly correlated with back injury. Someone's back muscles are in stretching position when he is bending his back. The discs of spines encounter high pressure, including the nerves inside. When this bending position happening repetitively, the discs will be weakened, and/or ending in disc rupture, or called herniation [7]. Symptoms of this condition were include back pain, strain, and cramp.

In addition, workers' arms were higher than their shoulders in some activities. In carrying process, moreover, their heads also supported the load along the process. This condition will possibly end up in neck stiffness, neck cramp, and also neck injury.

\subsection{Tool Design}

After considering the workers postures along the manual material handling and also their ideas of improving the process, a trolley was chosen. Fig. 3 displays the design of this trolley. 

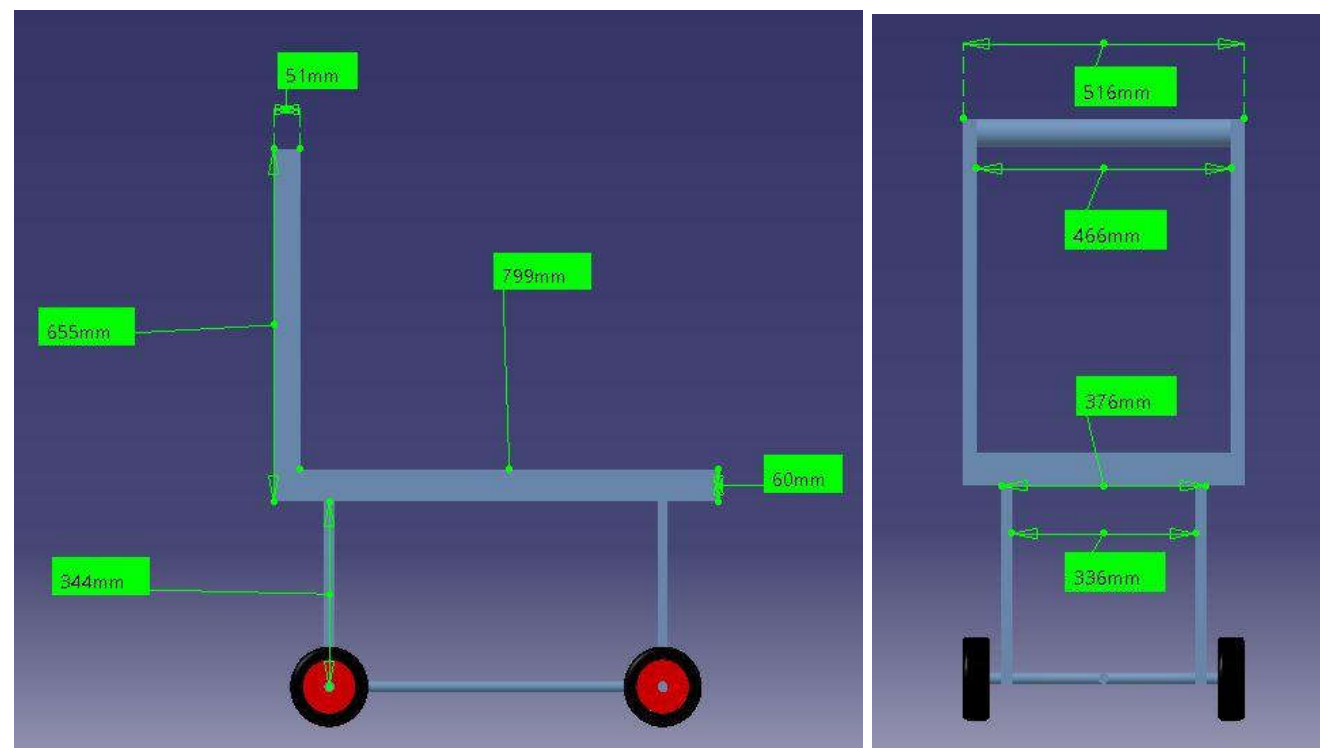

Fig. 3. Trolley design (side and front view).

The trolley was designed using Indonesian anthropometry dimensions, applying 95 percentile of men. The trolley height was $1074 \mathrm{~mm}$, equivalent with Indonesia populations elbow height. The diameter of the handle was also adjusted to Indonesian hand grip, which was $51 \mathrm{~mm}$. The height of sack base was $544 \mathrm{~mm}$, equivalent with Indonesian anthropometry knee height dimension.

\subsection{Improved Condition}

Applying the trolley proposed, analysis of working postures using OWAS was made once again. Fig. 4 shows the lifting and lowering process with CATIA software, while Fig. 5 presents the carrying process.
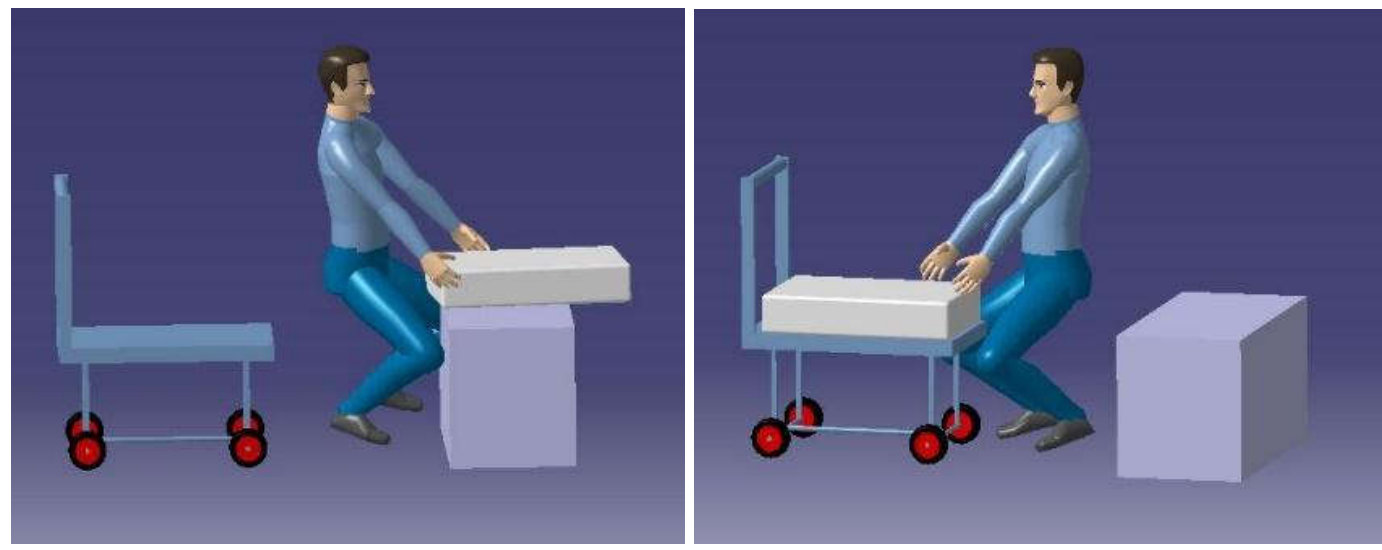

Fig. 4. Lifting and lowering load with trolley. 

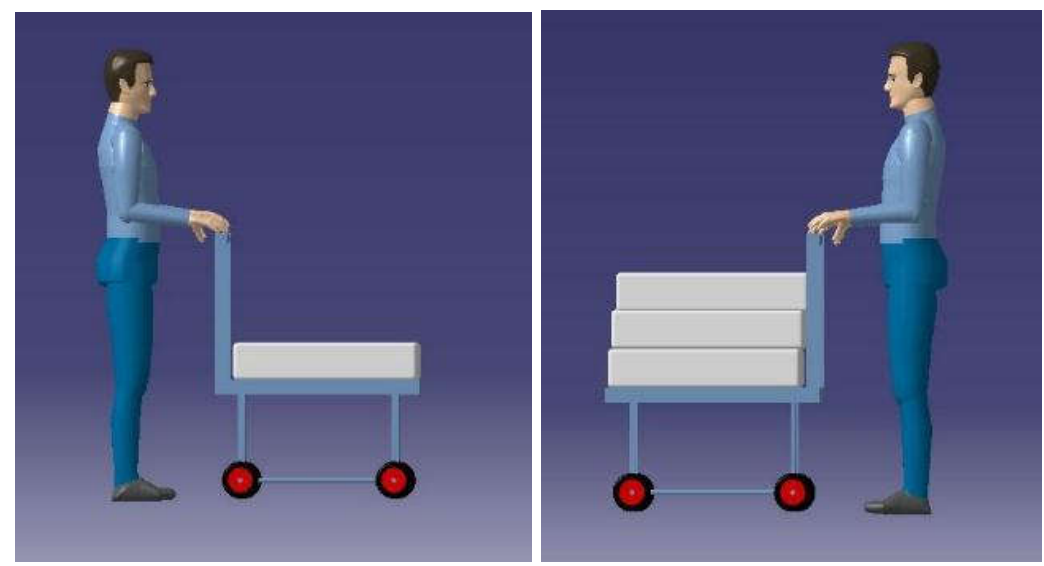

Fig. 5. Carrying load with trolley.

The lifting and lowering process with trolley resulted in OWAS score of category 2 (Corrective actions required in the near future), lower than the existing condition. Surprisingly, the carrying process was resulted in OWAS score of category 1 (No actions required), much lower than the existing condition.

Furthermore, the handling activity using trolley will be more efficient than the existing condition, since workers can carry two to three sacks at one time. The more efficient handling process means the faster workers finish their tasks, the more kind of tasks they can handle, the more saving company can make, and hopefully the more profit company can get.

Additionally, to maintain the minimum musculoskeletal risks during material handling, a base of $544 \mathrm{~mm}$ of height need to be provided. The maximum number of stacking suggested is ten. Therefore, the OWAS score could be maintained in category 1 or 2 , which is consider low risks.

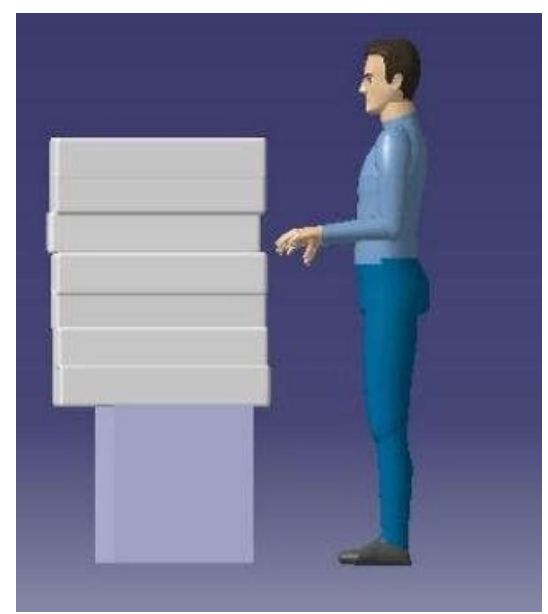

Fig. 6. Pile of powder sacks with proposed base.

\section{Conclusion and Further Study}

The existing condition of unloading process of sweet whey powder in CV Cita Nasional were carried out in high musculoskeletal risks, assessed by the worker postures using OVAKO Working Posture Analysis System (OWAS). Therefore, a trolley was designed in Indonesian anthropometry dimensions to help minimize the risks. Later, the lifting, carrying, and lowering activities with the proposed tool could be conducted in lower OWAS score, interpreted as lower musculoskeletal risks. 
Further study can be performed on other type of work that involving manual handling using the procedure in this study. More anthropometry data could be involved in the future study, applying Indonesian population from [8]. Additional biomechanics analysis can also be conducted on the present object, for example using electromyography (EMG) method as in [9], to make sure that the tool designed is significantly minimizing the MSDs risks.

\section{References}

1. A. M. Basahela, Investigation of work-related Musculoskeletal Disorders (MSDs) in warehouse workers in Saudi Arabia. Procedia Manufacturing, 3, 4643-4649 (2015)

2. Canadian Centers for Occupational Health \& Safety, WMSDs, http://www.ccohs.ca/oshanswers/diseases/rmirsi.html, Retrieved on 7 October 2016 (2014)

3. E. J. Wright, R. A. Haslam, "Manual Handling Risks and Controls in A Soft Drinks Distribution Centre", Applied Ergonomics, 30 (4), 311-318, (1999)

4. NIOSH, Musculoskeletal Disorders and Workplace Factors: A Critical Review of Epidemiologic Evidence for Work Related Musculoskeletal Disorder, NIOSH: Centers of Disease Control and Prevention (1997)

5. NIOSH, Ergonomic Guidelines for Manual Material Handling, NIOSH Publications Disseminations, Columbia (2007)

6. O. Karhu, "Correcting working postures in industry: A practical method for analysis", Applied Ergonomics, 8(4), 199-201 (1977)

7. D. B. Chaffin, G. B. J. Andersson, B. J. Martin, Occupational Biomechanics, John Wiley \& Sons, New York (1999)

8. A. Widyanti, M. Mahachandra, A. Wranitisandhini, A. Rahim, "Development of web based information system for Indonesian anthropometry data", Proceeding of APCHIErgoFuture 2010, 669-673 (2010)

9. B. Widjasena, P. Sinaga, H. Prastawa, "Participatory approach in designing tea picker bag to reduce musculoskeletal disorders at Medini Farm, Limbangan District, Kendal Regency", Proceeding of ErgoFuture 2006: International Symposium on Past, Present, and Future Ergonomcis, Occupational Safety and Health, 65-69 (2006) 